\title{
THIN-WALLED TIMBER STRUCTURES
}

\author{
Benoit P. Gilbert ${ }^{(1)}$, Steven B. Hancock ${ }^{(1)}$, Henri Bailleres ${ }^{(2)}$ \\ ${ }^{(1)}$ Griffith School of Engineering, Griffith University, Australia \\ (2) Salisbury Research Centre, Department of Agriculture, Fisheries and Forestry, Queens- \\ land Government, Australia
}

\begin{abstract}
Due to their efficiency, lightweight, ease of erection and low cost, steel and aluminium thin-walled structures have become very popular in the construction industry over the past few decades. Applications include roof and wall systems (purlins and girts), storage racks, and composite concrete and steel slabs. The effectiveness of these structures lies in the cross-sectional shape of the profiles which enhances their strength by controlling the three fundamental buckling modes: local, distortional, and global. However, despite the attractiveness of these structures, steel and aluminium are greenhouse gas intensive materials and do not produce sustainable structural products. This paper presents an investigation performed at the Griffith School of Engineering, Griffith University, which shows manufacturing these types of profiles in timber is possible. Short composite thinwalled timber Cee-sections (500 mm long) were fabricated by gluing together thin softwood (Araucaria cunninghamii) veneers (1 mm thick). Two types of Ceesections were considered, one with a web stiffener to increase the local buckling capacity of the profile and one without. The profiles were tested in compression and the test results are presented and discussed in the paper in terms of structural behaviour and performance. Further research directions are proposed in order to provide efficient and lightweight sustainable structural products to the timber industry.
\end{abstract}

\section{INTRODUCTION}

Cold-formed steel and aluminium thin-walled profiles are commonly used in the construction industry due to their efficiency, lightweight, ease of erection and low cost [1]. The worldwide market for these products is significant and estimated at more than two billions dollars. Typical industrial and civil engineering applications include roof and wall systems (purlins and girts), steel storage racks and composite concrete and steel slabs. Typical cold-formed steel profiles are shown in Figure 1.

Due to the nature of the manufacturing process, consisting of bending a thin sheet of metal to a desired cross-sectional shape, open profiles such as Cee- or Zeecross-sections are generally used. Three fundamental buckling modes, referred to as local, distortional and global (see Figure 2), can occur for these profiles and usually govern the compressive and bending strength. The section capacity for local buckling is typical enhanced by adding intermediate stiffeners to walls having significantly large width-to-thickness ratios (see Figure 1), while the section 
capacity for distortional buckling can be enhanced by changing the cross-sectional shape, mainly by adding lip stiffeners.

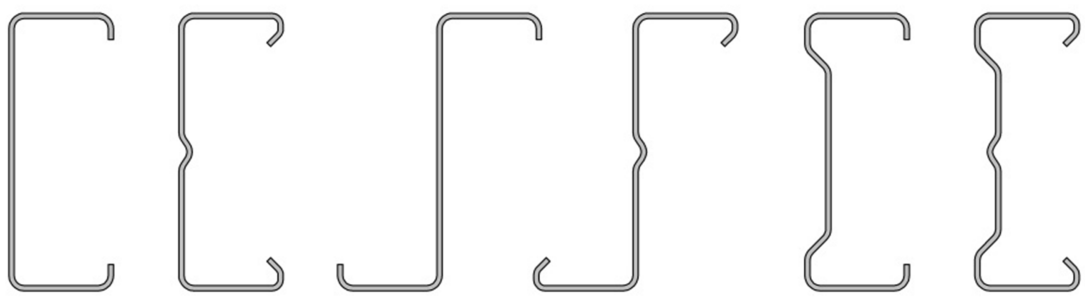

Figure 1: Examples of cold-formed steel profiles, with and without intermediate stiffeners

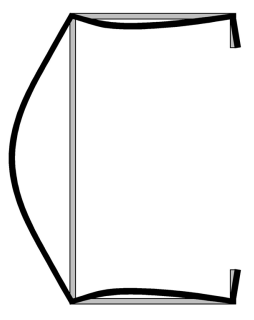

(a)

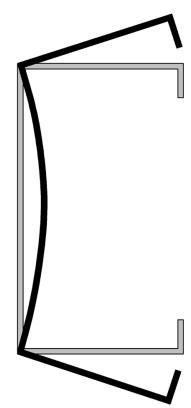

(b)

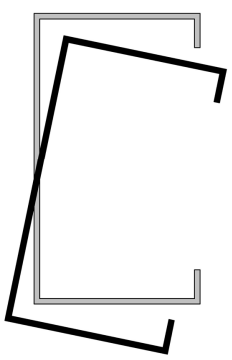

(c)

Figure 2: Fundamental buckling modes for thin-walled open cross-sections in compression, (a) local, (b) distortional and (c) global,

However, despite the attractiveness of these types of profiles, steel and aluminium are greenhouse gas intensive materials and do not produce sustainable structural products [2]. Manufacturing profiles similar to the ones shown in Figure 1 in timber is possible, but to the authors' best knowledge, has not yet been investigated in the published literature. This paper presents the first step of a study aiming at developing extra light and structurally sound timber profiles for applications including amongst others (i) emergency shelters which can be rapidly assembled and disassembled, (ii) purlins for major timber buildings, as a substitute to steel purlins currently used and (iii) wall stubs.

Short composite thin-walled timber Cee-sections (500 mm long) were fabricated by gluing together thin softwood (Hoop pine - Araucaria cunninghamii) veneers. Two types of Cee-sections were considered, namely one with a web stiffener to increase the local buckling capacity of the profile and one without, and this paper introduces the steps involved in the manufacturing process. The sections were tested in compression and the test results are presented and discussed in the paper in terms of structural behaviour and performance. Further research directions are also proposed. 


\section{INVESTIGATED SECTIONS}

\subsection{General}

Three sets of two $210 \mathrm{~mm}$ deep $\times 105 \mathrm{~mm}$ wide Cee-sections (with $50 \mathrm{~mm}$ lip stiffeners) were manufactured and investigated. The two cross-sections in a set are of different type. Type A cross-section had no intermediate stiffeners, as shown in Figure 3 (a), and the cross-section was designed so local buckling of the web would govern the strength of the profile. On the contrary, a web stiffener was added to the second type of cross-section (Type B), as shown in Figure 3 (b), so the local buckling capacity of the cross-section would theoretically be higher than the maximum compressive strength of the material. The nominal section properties of the cross-sections are given in Table 1.

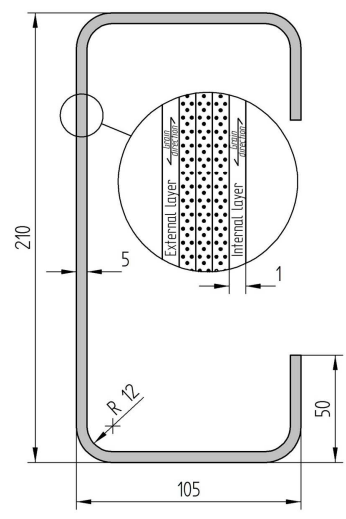

(a)

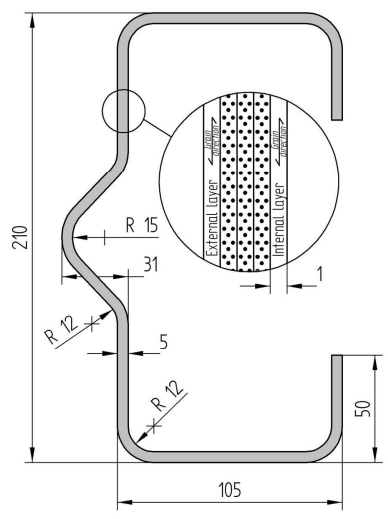

(b)

Figure 3: Cee-sections manufactured and tested, (a) Type A and (b) Type B

Each cross-section was composed of 5 layers of nominal $1 \mathrm{~mm}$ thick Hoop pine rotary sliced veneers. The grain of the three inner layers was orientated along the member longitudinal axis, while the grain of the two outer layers was perpendicular to the inner layers and orientated in the member transverse direction (see insert in Figure 3). In this configuration, the three inner layers would mainly resist the compressive load while also providing resistance against bending of the walls in the longitudinal direction, and the two outer layers would mainly provide resistance against bending of the walls in the transverse direction, therefore enhancing the local buckling capacity of the profile.

Table 1: Nominal section properties

\begin{tabular}{c|ccccc}
\hline Type & $\begin{array}{c}\text { Area } \\
\left(\mathrm{mm}^{2}\right)\end{array}$ & $\begin{array}{c}I_{\text {major axis }} \\
\left(\mathrm{mm}^{4}\right)\end{array}$ & $\begin{array}{c}I_{\text {minor axis }} \\
\left(\mathrm{mm}^{4}\right)\end{array}$ & $\begin{array}{c}\text { Warping } \\
\left(\mathrm{mm}^{6}\right)\end{array}$ & $\begin{array}{c}J \\
\left(\mathrm{~mm}^{4}\right)\end{array}$ \\
\hline A & 2375 & $1.58 \times 10^{7}$ & $3.92 \times 10^{6}$ & $4.97 \times 10^{10}$ & $1.98 \times 10^{4}$ \\
B & 2466 & $1.58 \times 10^{7}$ & $4.64 \times 10^{6}$ & $5.03 \times 10^{10}$ & $2.06 \times 10^{4}$ \\
\hline
\end{tabular}




\subsection{Manufacturing process}

Veneers were delivered in sheets of $1.2 \mathrm{~m} \times 1.3 \mathrm{~m}$ and sheets with a minimum number of or with no natural defects (knots, resin veins, etc...) were selected. Different veneer sheets were used for each layer constituting a profile. Yet, all crosssections in a set were manufactured from the same sheets, glued in the exact same order, allowing comparison between the two types of cross-sections in a set.

Each cross-section was manufactured as:

Step 1: Sheets were cut to size and veneers were soaked in water for 48 hours.

Step 2: The veneers were laid flat on a bench, with the grain in the appropriate orientation (see section 2.1), heated using a steamer and bent around a jig to form the cross-section.

Step 3: Each flat side of the cross-section was clamped to the jig, as seen in Figure 4 for Type B cross-section.

Step 4: The jig was placed in an oven at $40^{\circ} \mathrm{C}$ for about 12 hours, till the bends were dried and hold their shapes.

Step 5: The veneers were unclamped and removed from the jig, further left to dry in the oven for about 4 hours, and stored in an air-conditioned room until their moisture content reached equilibrium.

Step 6: The veneers were glued around the jig at ambient temperature with Resorcinol formaldehyde structural adhesive. Similar to Step 3, each flat side of the cross-section was clamped to the jig. Rubber sheets were inserted between the veneers and the clamping plates to uniform the applied pressure. The glue was left to set for a minimum of 48 hours before unclamping the cross-section.

Step 7: The excess wood in the lip stiffeners were cut to form the final crosssections.

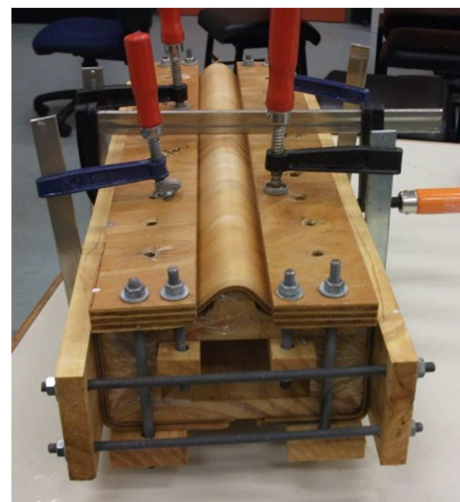

Figure 4: Type B Cee-section during manufacturing Step 3

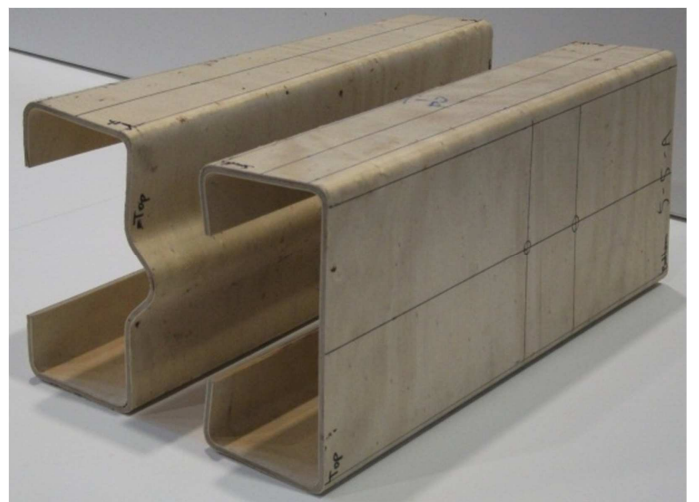

Figure 5: Final Cee-sections

To simplify the manufacturing process and obtain more reliable products, especially for the bends, a vacuum press is planned to be used in the future. Figure 5 shows a photo of the final products. 
To determine the mechanical properties of each set of cross-sections, flat panels were also manufactured using the same sheets as their associated cross-sections glued in the exact same order and orientation. Before testing, cross-sections and flat panels were left in an air-conditioned room until their moisture content reached equilibrium.

\section{MATERIAL TESTING}

\subsection{MOE parallel to grain}

The Modulus of Elasticity (MOE) parallel to the grain of the veneers used to manufacture the cross-sections was estimated using a non-destructive resonance method [3]. A 300 to $500 \mathrm{~mm}$ long $\times 30 \mathrm{~mm}$ wide sample of each veneer was simply supported on rubber bands and impacted with a hammer. The natural frequency of the tested sample was recorded using a microphone and analysed using the software BING $^{\circledR}$ (Beam Identification by Nondestructive Grading) [4]. Table 2 gives the measured MOE parallel to the grain of each veneer used.

Table 2: Modulus of Elasticity for each veneer used

\begin{tabular}{c|ccccc}
\hline & \multicolumn{5}{|c}{ MOE parallel to the grain (MPa) } \\
Set & Layer 1 (Inside) & Layer 2 & Layer 3 & Layer 4 & Layer 5 (Outside) \\
\hline 1 & 12969 & 13279 & 11955 & 12471 & 14648 \\
2 & 20399 & 19317 & 16811 & 19164 & 15113 \\
3 & 17187 & 16186 & 16725 & 18776 & 14401 \\
\hline
\end{tabular}

\subsection{MOR parallel to the longitudinal axis}

The flat panels of each set of cross-sections were cut in four and reglued to form $20 \mathrm{~mm}$ nominal thick panels. Nominal $100 \mathrm{~mm}$ long $\times 46 \mathrm{~mm}$ wide samples were then tested in compression parallel to the longitudinal axis of the cross-sections, in a $500 \mathrm{kN}$ capacity MTS testing machine, following the method proposed in the Australian and New-Zealand Standard AS/NZS 4357.2 [5]. The apparent Modulus of Rupture $M O R_{a p p}$ is calculated as,

$$
M O R_{a p p}=\frac{P_{\max }}{b d}
$$

where $P_{\max }$ is the maximum applied load, and $b$ and $d$ are the measured width and depth of the sample, respectively. Table 3 gives the average apparent MOR for each set of cross-sections.

Table 3: Average apparent Modulus of Rupture for each set of cross-section

\begin{tabular}{c|ccc}
\hline Set & Number of tests & Average $M O R_{a p p}(\mathrm{MPa})$ & $\mathrm{CoV}$ \\
\hline 1 & 2 & 29.1 & 0.014 \\
2 & 3 & 36.3 & 0.034 \\
3 & 3 & 34.8 & 0.023 \\
\hline
\end{tabular}




\section{STUB-COLUMN TESTS}

\subsection{Test set-up}

The profiles were tested in compression in a $500 \mathrm{kN}$ capacity MTS testing machine in which the lower platen was fixed, while the upper platen was mounted on a half sphere bearing which could rotate so as to provide full contact between the platen and the specimen, as shown in Figure 6. The tests were performed in displacement controlled at a stroke rate of $0.6 \mathrm{~mm} / \mathrm{min}$. Load was applied through the theoretical centroidal axis of the cross-sections.

This test arrangement, i.e. consisting of testing short columns of lengths typically less than twenty times their least radius of gyration, aims at determining the effect of local buckling on the column performance and allows the determination of the column strength (or section capacity for local buckling) [6].

For Type A cross-sections only, three Linear Variable Displacement Transducers (LVDT) recorded the horizontal displacements of the centreline of the web at heights of $175 \mathrm{~mm}$ (LVDT 2), $250 \mathrm{~mm}$ (mid-height - LVDT 1) and $325 \mathrm{~mm}$ (LVDT 3), and one LVDT recorded the horizontal displacement of the centreline of the north flange at mid-height (LVDT 4), as shown in Figure 6.

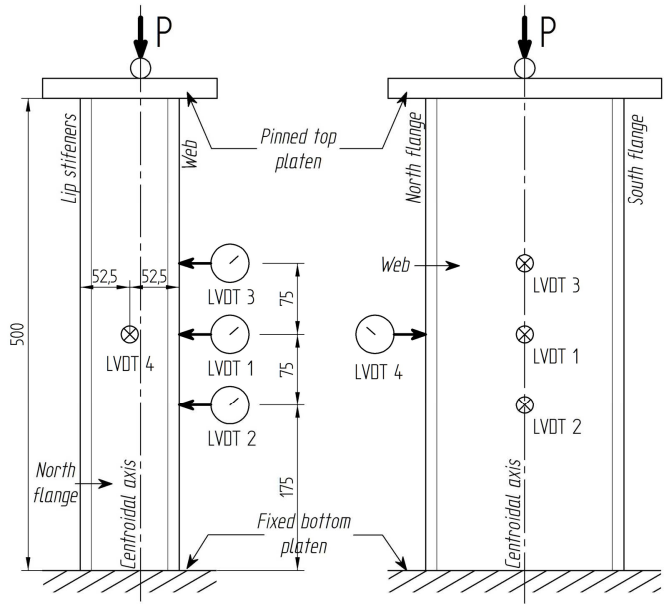

(a)

(b)

Figure 6: Stub-column test set-up (shown for Type A cross-section), elevations: (a) flange view, (b) web view

\subsection{Test results}

Table 4 gives the recorded section capacity $N_{s}$ of each cross-section (defined as the maximum applied load) and the associated squash load $N_{\text {squash }}$, representing the upper bound capacity of the cross-section, defined as,

$$
N_{\text {squash }}=M O R_{\text {app }} \times A
$$


where $M O R_{a p p}$ is given in Table 3 and $A$ is the nominal cross-sectional area given in Table 1.

Table 4: Stub-column test results

\begin{tabular}{c|ccc|ccc}
\hline & \multicolumn{4}{|c|}{ Type A } & \multicolumn{3}{c}{ Type B } \\
Set & $N_{s}(\mathrm{kN})$ & $N_{\text {squash }}(\mathrm{kN})$ & $N_{s} / N_{\text {squash }}$ & $N_{s}(\mathrm{kN})$ & $N_{\text {squash }}(\mathrm{kN})$ & $N_{s} / N_{\text {squash }}$ \\
\hline 1 & 41.3 & 69.1 & 0.60 & 54.7 & 71.8 & 0.76 \\
2 & 47.5 & 86.2 & 0.55 & 63.5 & 89.5 & 0.71 \\
3 & 49.8 & 82.7 & 0.60 & 61.3 & 85.8 & 0.71 \\
\hline Average & 46.2 & 79.3 & 0.58 & 59.8 & 82.4 & 0.73 \\
\hline
\end{tabular}

It can be seen from Table 4 that the addition of the web stiffener in Type B crosssection resulted in an increased average section capacity of $29 \%$ for an increased cross-sectional area of 3.8\%. Type A and B cross-sections reached an average of $58 \%$ and $73 \%$ of their upper bound capacity $N_{\text {squash }}$, respectively.

Figure 7 and Figure 8 plots the recorded displacements of the four LVDTs and shows the failure mode, respectively, for the Type A cross-section of the third set. It can be noticed in Figure 7 and Figure 8 a large post-buckling behaviour, similar to the one encountered in steel structures.

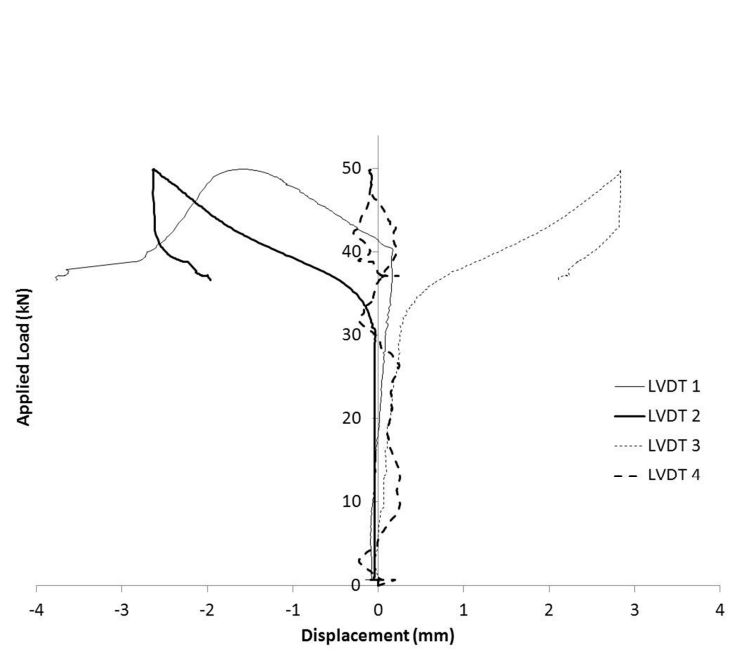

Figure 7: Test results for set $n^{\circ} 3$, Type A cross-section

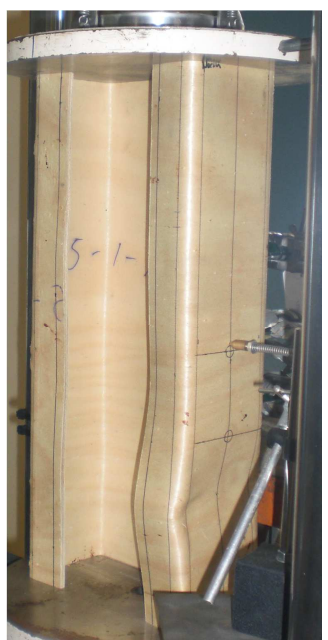

Figure 8: Failure mode for set $\mathrm{n}^{\circ} 3$, Type A cross-section

\subsection{Comparison with cold-formed steel structures}

Using typical densities of $550 \mathrm{~kg} / \mathrm{m}^{3}$ for hoop pine [7] and 7,850 kg/m $\mathrm{m}^{3}$ for steel, the cross-sectional area required for a steel profile to equal the linear weight of the studied cross-sections is in the range of 166 (Type A cross-section) to $173 \mathrm{~mm}^{2}$ (Type B cross-section). This range of cross-sectional area would lead to a maximum section capacity $N_{s}$ of $74.7 \mathrm{kN}$ to $77.9 \mathrm{kN}$ for $450 \mathrm{MPa}$ graded steel, i.e. 
about $39 \%$ and $22 \%$ greater than the average observed capacities of cross-sections Type A and B, respectively. Yet, these steel profiles would likely have slender wall elements leading to low local buckling capacities and therefore reduced column strength.

For instance, the C7510 cold-formed steel Cee-section (75 mm deep and $1.0 \mathrm{~mm}$ wall thickness) from the Australian manufacturer Lysaght [8] has a nominal crosssectional area of $162 \mathrm{~mm}^{2}$ and a stub-column capacity of $46.2 \mathrm{kN}$ [9] for $450 \mathrm{MPa}$ graded steel. This capacity is equal and $29 \%$ less than the average observed capacities for cross-sections Type A and B respectively. Moreover, the bending stiffness $E I$ about the major axis of bending of the C7510 is equal to $2.88 \times 10^{10} \mathrm{~N} \cdot \mathrm{mm}^{2}(E=$ $200,000 \mathrm{MPa}$ and $I=1.44 \times 10^{5} \mathrm{~mm}^{4}$ ), while the bending stiffness of Type A crosssection is equal to $1.23 \times 10^{11} \mathrm{~N} \cdot \mathrm{mm}^{2}(E=13,000 \mathrm{MPa}$ at $12 \%$ moisture content [7] and $I=9.45 \times 10^{6} \mathrm{~mm}^{4}$ when only considering the three inner layers resisting bending), i.e. 4.3 times greater than the $\mathrm{C} 7510$ steel profile.

Similarly, Yap and Hancock [10] performed stub-column tests on $128 \mathrm{~mm}$ deep and $0.42 \mathrm{~mm}$ wall thickness complex high strength cold-formed steel open profiles. The nominal yield stress of the profiles was equal to $550 \mathrm{MPa}$, the crosssectional area to $158 \mathrm{~mm}^{2}$ and the average tested stub-column capacity to $45.7 \mathrm{kN}$, i.e. $1 \%$ and $31 \%$ less than the average observed capacities for cross-sections Type A and B respectively. The profiles tested in [10] had a bending stiffness about the strong axis of bending equal to $4.74 \times 10^{10} \mathrm{~N} \cdot \mathrm{mm}^{2}\left(I=2.37 \times 10^{5} \mathrm{~mm}^{4}\right)$, i.e. about 2.6 times less than the studied timber profiles.

\section{FUTURE STUDIES}

By advancing the structural and mechanical knowledge on thin-walled timber structures, the final aim of this project is to eventually develop design rules, so engineers can safely use the proposed products. Current researches involve developing a Finite Element model to reproduce the test results presented in this paper. Moreover, the ultimate strength and post-buckling behaviour of thin-walled structures is significantly influenced by geometric imperfections [11] and understanding the influence of the moisture content on these imperfections, and therefore on the capacity of the cross-section, is important. Additional proposed future research also includes (i) developing joining details to connect manufactured lengths of cross-sections, (ii) testing and understanding the structural behaviour of long columns and beams, (iii) extend the Finite Strip Method [12] currently used to determine the buckling curves of thin-walled isotropic and orthotropic materials to composite materials, and (iv) extend the Direct Strength Method [13] currently used to design cold-formed steel profiles to thin-walled timber profiles.

\section{CONCLUSION}

This paper presented an experimental investigation on thin-walled timber structures. $210 \mathrm{~mm}$ deep, $105 \mathrm{~mm}$ wide and $5 \mathrm{~mm}$ wall thickness composite timber Cee-sections were fabricated by gluing together thin softwood (Hoop pine - Araucaria cunninghamii) veneers. Two types of cross-section, with and without inter- 
mediate web stiffener, have been investigated. The manufacturing process is detailed in the paper. Stub-column tests were performed and results show that (i) manufacturing structurally sound thin-walled timber structures is possible, (ii) the investigated cross-sections have significant post-buckling behaviour and (ii) are able to compete with cold-formed steel products with similar or greater weight to compressive capacity ratio and significantly higher bending stiffness.

\section{REFERENCES}

[1] G.J. Hancock, Design of cold-formed steel structures (to AS/NZ 4600:2007) 4th Edition, (Australian Steel Institute), North Sydney, Australia, 2007.

[2] H. Yan, Q. Shen, L.C. Fan, Y. Wang, L. Zhang "Greenhouse gas emissions in building construction: A case study of One Peking in Hong Kong", Building and Environment, 45, 949-955, 2010.

[3] L. Brancheriau, H. Bailleres "Natural vibration analysis of clear wooden beams: a theoretical review", Wood Science and Technology, 36, 347-365, 2002.

[4] CIRAD, BING® (Beam Identification by Nondestructive Grading) software, http://ur-bois-tropicaux.cirad.fr/produits/bing/usage, Accessed on 23/04/2013.

[5] AS/NZS 4357.2, Structural laminated veneer lumber, Part 2: Determination of structural properties - Test methods, Standards Australia, Sydney, Australia, 2006. [6] T.V. Galambos, Guide to stability design criteria for metal structures, (Wiley and Sons), New York, U.S.A., 1998.

[7] R.S.T. Kingston, The mechanical properties of Queensland grown hoop pine, Proj.TM.9-7, Final report, Commonwealth of Australia - Council for Scientific and Industrial Research - Division of Forest Products, South Melbourne, Australia, 1947.

[8] BlueScope Steel Limited, LYSAGHT® Zed \& Cee Purlins and Girts, http://www.lysaght.com/go/product/lysaght-zed-and-cee-purlins-and-girts,

Accessed on 23/04/2013.

[9] AS/NZS 4600, Cold-formed steel structures, Standards Australia, Sydney, Australia, 2005.

[10] D.C.Y. Yap, G.J. Hancock "Experimental Study of Complex High-Strength Cold-Formed Cross-Shaped Steel Section", ASCE Journal of Structural Engineering, 134, 1322-1333, 2008.

[11] B.W. Schafer, Z. Li, C.D. Moen "Computational modeling of cold-formed steel", Thin-Walled Structures, 48, 752-762, 2010.

[12] Y.K. Cheung, Finite Strip Method in structural analysis, (Pergamon Press, Inc.), New York, N.Y., 1976.

[13] B.W. Schafer, "Designing cold-formed steel using the direct strength method", Proceedings of the 18th International Specialty Conference on ColdFormed Steel Structures (Eds.: R.A. LaBoule, W.W. Yu), Orlando, Florida, 475490, 2006. 